\title{
Temporal and spatial complementarity of wind and solar resources in Lower Silesia (Poland)
}

\author{
Jakub Jurasz ${ }^{1}$, Marcin Wdowikowski ${ }^{2}$, Bartosz Kaźmierczak ${ }^{3,}$ and Paweł Dąbek ${ }^{4}$ \\ ${ }^{1}$ AGH University, Faculty of Management, 30-059 Kraków, 30 Mickiewicza Av., Poland \\ ${ }^{2}$ Institute of Meteorology and Water Management - National Research Institute, 01-673 Warsaw, \\ Podleśna 61, Poland \\ ${ }^{3}$ Wrocław University of Science and Technology, Faculty of Environmental Engineering, \\ PlacGrunwaldzki 13, 50-377 Wrocław, Poland \\ ${ }^{4}$ Wrocław University of Environmental and Life Sciences, Institute of Environmental Development \\ and Protection, Grunwaldzki 24, 50-363 Wrocław, Poland
}

\begin{abstract}
This paper investigates the concept of temporal and spatial complementarity of wind and solar resources in Lower Silesia (southwester Poland). For the purpose of our research we have used hourly load and energy yield from photovoltaics and wind turbines covering period 2010-2014. In order to assess the spatial complementarity we have divided the considered voivodeship into 74 squared regions with maximal area of $400 \mathrm{~km}^{2}$. The obtained results indicate an existence of temporal complementarity on a monthly time scale and a positive correlation between load and wind generation patterns (also on a monthly time scale). The temporal complementarity for hourly time series in relatively low but has potential to smooth the energy generation curves.
\end{abstract}

\section{Introduction}

The advent of large scale variable renewable energy sources (VRES) mainly in form of photovoltaics and wind turbines is a result of a transition from power system based upon finite fossil fuels to a sustainable one utilizing the abundant and inexhaustible renewable resources. However, the inherently intermittent nature of solar radiation and wind speed makes them a non-dispatchable energy sources. Therefore, their integration to the national power systems dominated by relatively slowly ramping-up and down coal are nuclear power plants is an arduous and complicated task. Considering the increasing installed capacity in photovoltaics (PV) and wind turbines (WT) and the fact that they start to play a significant role in covering the energy demand a need arises to address the problem of integration [1].

So far, various approaches and methods have been presented which aim at facilitating the process of VRES integration. Accordingly to [2] this problem can be solved by applying following solutions:

\footnotetext{
*Corresponding author: bartosz.kazmierczak@pwr.edu.pl
} 
- interconnecting geographically distributed inherently variable energy sources (e.g. solar, tidal or wind), where a spatial distribution smoothing effect can be observed. Such effect has been presented by inter alia [3] in case of interconnected European energy system;

- to couple variable but temporally complementary (solar and wind) energy sources in one hybrid generator, or to connect non-dispatchable power source with a dispatachble one (hydropower) to fill the gaps between demand and generation. The concept of coupling variable PVs with hydropower in form of run-off-river power plant with pondage has been presented in [4];

- to apply so called demand side management (DSM) od demand-response management (DRM) which can shift flexible loads to a time when more electricity will be available from VRES [5];

- to couple VRES generators with energy storage (on a smaller scale batteries [6], fuel cells [7], compressed air [8], pumped storage hydroelectricity [9] to overcome the problem of mismatch between supply and demand;

- to over-size the VRES peak generation in such a way that when the supply is greater than demand the remaining power can be used to produce hydrogen for transportation and heating purposes;

- to store the energy in electric vehicles which are believed to play a significant role in future transport systems [10];

- to apply forecasting methods, for predicting the energy/power generation from selected VRES sources like wind [11] solar [12] to better plan the power system operation.

From the perspective of preparing a strategy for the power system development all above mentioned concepts may play a significant role and heavily impact the decisions which are about to be made. Usually, it is not sufficient to choose only one solution because the intermittent nature of solar and wind generation and added to it variability of energy demand is too. Therefore it is very common to combine the effect of complementary in time domain solar and wind resources with energy storage in form of batteries or pumped storage hydroelectricity depending on the installed capacity and load to be covered.

Unfortunately, the spatial and temporal complementarity of wind and solar resources is not a common problem addressed by meteorologist or developers of national power systems (the advent of VRES in many energy systems is an issue of several last years). Therefore, the aim of this paper is to present the current state of the art in area of studies on the temporal and spatial complementarity between wind and solar energy sources. Both from the worldwide and national (Poland) perspective. To expand the current state of knowledge we will perform an analysis of spatial and temporal complementarity between wind and solar resources on the area of Lower Silesia which is a district laying in the southwestern part of Poland. Apart from assessing their complementarity on an hourly, daily and monthly time scale we will address the problem of their relation to the load curve.

\subsection{Worldwide studies}

Usually in the scientific literature the impact of variable renewable energy sources temporal and spatial complementarity is investigated in order to show that the sudden drop in power generated in one source can be replaced by a simultaneous increase in power provided by another source. A common way to assess the complementarity on a various temporal and spatial scales is to use the coefficient of correlation (CC) which ranges from -1 to 1 . Where " -1 " denotes a perfect complementarity and "1" means that two considered sources tend to exhibit exactly the same energy generation patterns. In reality the CC values close to "-1" 
are not observed. The idea laying behind the energy sources temporal complementarity can be explained by means of a two sine functions from which one is out of phase by $\pi$ (see Fig. 1).

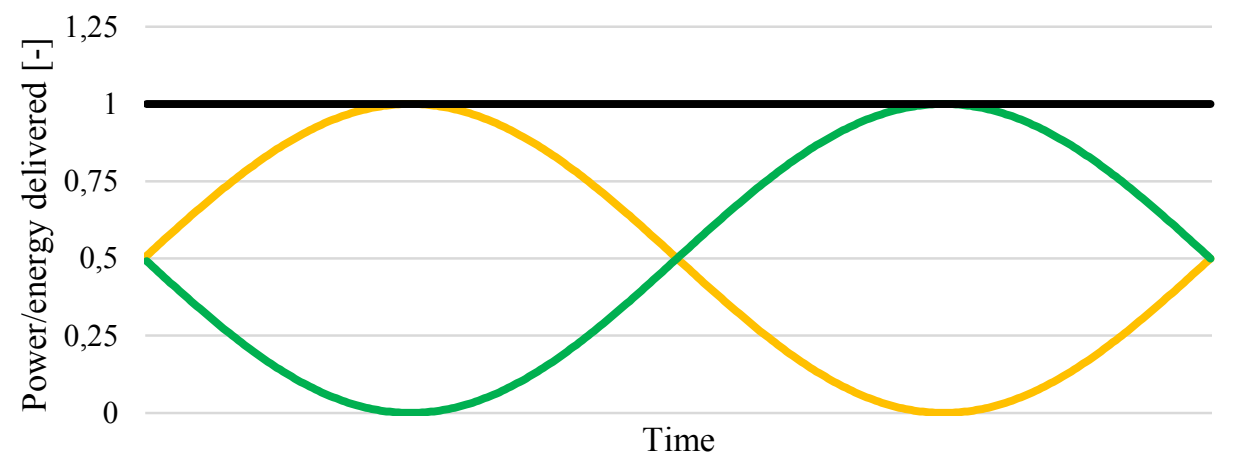

Time

First source $\longrightarrow$ Second source $\longrightarrow$ Combined power/energy yield

Fig. 1. Ideal temporal complementarity between two energy sources.

The available scientific literature concentrated mainly on individual sites for which measurements on solar radiation and wind speed were available as well as on larger regions (country, district level) where data has been interpolated based on measurements available from several stations.

For an Ontario province of Canada [13] a three years long hourly time series of solar radiation and wind speed were used to assess their spatial and temporal complementarity. The results presented clearly show that spatial dispersion of wind and solar resources smooths their power output. Another research performed for Italy based on a one year long hourly time series [14] based on a Monte Carlo approach proved their strong temporal complementarity on a monthly time scale. Interesting study performed for northeast Brazil [15] has shown that availability of solar and wind resources during the dry period can be used to reinforce hydropower in order to increase the water retention for irrigation purposes. An analysis performed for China's solar and wind resources [16] has shown that their proper spatial distribution can reduce the occurrence of zero and peak power yield hours. A paper [17] analysing solar and wind complementarity with regard to the load demand in Australia has shown that combined resources can effectively deliver energy to the grid when it experiences peaks. [18] applied a simulated annealing method to optimally distribute the solar and wind generators over the Iberian Peninsula and obtained results support the existence of a beneficial spatio-temporal complementarity. Another analysis [19] performed for a Fernando de Noronha Island (Brazil) has shown that both processes (wind speed and solar radiation) demonstrate persistent correlations and cross-correlations. Over the recent months an important paper [20] which summarizes the recent research in area of VRES integration and ways of mitigating their inherently variable nature has been published. This review paper concludes that there exist three climatic regimes which drive the variability of renewable energy sources and the load.

\subsection{Related works on solar/wind complementarity in Poland}

In Poland the problem of wind and solar resources complementarity has not been widely addressed. This results from the fact that renewable energy sources (RES) in Poland are commonly perceived as a threat to the coal dominated energy sector. In general opinion 
they not only may disrupt its operation but in consequence decrease the demand on national abundant hard and brown coal extraction. However, the European Union regulations oblige Poland to increase the share of RES in our energy portfolio. This however, cannot be entirely realized based on dispatachble (biomass, geothermal or biogas) resources from several mainly economic reasons. Therefore, the picking up role of PVs and WTs in Polish energy sector in unavoidable.

Hereunder, we summarize the so far conducted research. A study published in the year 2013 [21] for solar and wind conditions similar to Polish concludes that an even mix in terms of installed capacity in PVs a WTs should be optimal for Polish power system considering the temporal complementarity of those two resources. A three years later published paper [22] investigated the temporal complementarity of wind, solar and water resources in Piła (north-western Poland). The obtained results have shown that a beneficial complementarity between wind and solar energy on a monthly scale and between solar and hydropower on an annual level. A research conducted in the area of Energa - Operator SA (a local power system operator) [23] was based on real data from existing wind and solar parks. In general when high power output was observed in case of wind generation than the power generated was significantly smaller and vice versa. Another research paper [24] analysed the temporal complementarity of wind, solar and hydrokinetic energy source in two locations (Lębork and LądekZdrój). The observed there values of solar and wind complementarity were not very spectacular however it is important to note that this analysis was conducted form a wind speed measured at 10 meters above sea level which is rather typical for residential not commercial scale wind turbines. The results presented in [22, 24] has been expanded for additional locations in Poland and authors developed a mathematical model which aims at selecting the optimal distribution of wind and solar parks in Poland (considering the spatio-temporal complementarity) aiming at minimizing the variability of their combined energy yield. Presented in the next sections analysis are a follow up of the results presented in [21-25] and investigate the spatial and temporal complementarity of wind and solar resources in Lower Silesia.

\section{Data and methods}

First of all it is important to underlie that for the purpose of our research we have divided the considered region (Lower Silesia voivodship) into 74 smaller squared regions ( 20 by 20 kilometres) which centres of gravity fit into its borderlines. However, the data from ground measurements is not available for all selected locations. Therefore the first step of our analysis was to compare satellite and ground measurements in terms of their coherence. Results of conducted analysis are presented on Fig. 2 and 3. Clearly the solar radiation measurements obtained from satellite and ground stations exhibit significantly greater correlation. The relatively low values of coefficient of determination $\left(\mathrm{R}^{2}\right)$ in case of wind speeds can be explained by the fact that wind is locally definitely more variable. What is more ground measurements are usually representative for selected location whereas satellite ones have much more coarse resolution (20x20 kilometres). Considering above we have decided to base our research on satellite measurements.

For the purpose of our calculations we have used hourly irradiation and wind speed time series available at [26] covering year 2010-2014. We have also used six time series obtained from [27] which were generated based on the ground measurements. Time series from [26], were then validated against those from [27], (please refer to section 2.2 for deeper analysis). The obtained results justified the application of satellite generated time series from [26] for the purpose of our research. In case of wind speed time series (measured at 10 m.a.s.l.) we have used the power law [28] to calculate the wind speed which might be observed at the hub height (100 meters) of the considered Vestas V90 wind 
turbine. To juxtapose energy yield patterns with energy demand we have used hourly energy demand time series representative for Poland - such data has been downloaded from [29]. Over the year 2014 the cumulative energy consumption in Lower Silesia amounted to $13.8 \mathrm{TWh}$.
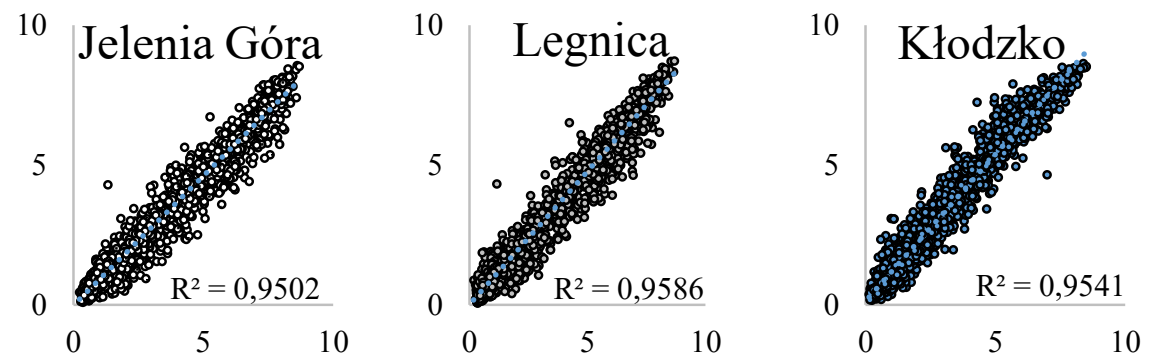

Fig.2. Solar irradiation measurements from satellite (OY) and ground measurements (OX) measurements both in [kWh/day] - daily sums over 2010-2014.
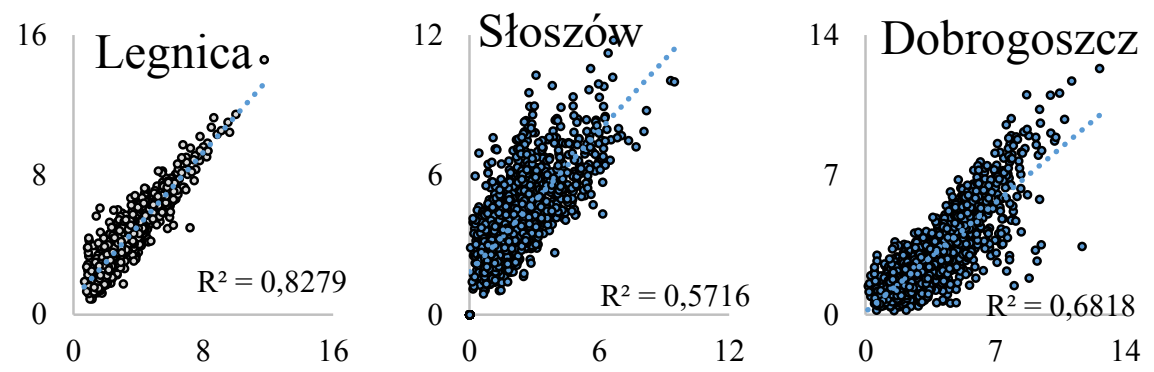

Fig.3. Wind speed measurements from satellite (OY) and ground measurements (OX) measurements both in $[\mathrm{m} / \mathrm{s}]$ - daily meansover $2010-2014$.

\subsection{Energy yield estimation}

The energy yield from $E_{i, j, k}^{P V}(\mathrm{kWh})$ a photovoltaics generator $P_{k}^{P V}(\mathrm{~kW})$ in given location $k$ and time $i, j$ (here time step $t=1$ hour)depends on global horizontal irradiation $H_{i, j, k}$ $\left(\mathrm{kWh} / \mathrm{m}^{2}\right)$ and air temperature $T_{i, j, k}[30]$, temperature dependent efficiency reduction factor $\mu$, cell temperature in the standard testing conditions $T^{S T C}[31]$ and the overall efficiency $\eta^{P V}$ of all remaining system components (inverter efficiency, wire losses, shading etc).

$$
E_{i, j, k}^{P V}=\frac{H_{i, j, k}}{H^{S T C}}\left[1-\mu \frac{1}{{ }^{o} C}\left(T_{i, j, k}-T^{S T C}\right)\right] P_{k}^{P V} \eta^{P V} t
$$

The energy generated $E_{i, j, k}^{W T}(\mathrm{kWh})$ by a given type of wind turbine over time $t=1$ hour (here Vestas V90 with rated power $P_{k}^{W T}=2000 \mathrm{~kW}$ ), depends on the observed wind speed $v_{i, j, k}(\mathrm{~m} / \mathrm{s})$ at the hub height as well as the parameters of the turbine itself especially: power curve $p(v)(\mathrm{kW})$, wind cut in $v_{\text {cut-in }}$, rated $v_{\text {rated }}$ and cut off $v_{c u t-o f f}$ speeds $(\mathrm{m} / \mathrm{s})$.

$$
E_{i, j, k}^{W T}=\left\{\begin{array}{c}
0 \text { for } v_{i, j, k} \in\left(0, v_{c u t-i n}\right) \cup\left(v_{\text {cut }- \text { off }},+\infty\right) \\
P_{k}^{W T} t \text { for } v_{i, j, k} \in\left(v_{\text {rated }}, v_{\text {cut }- \text { off }}\right) \\
P_{k}^{W T} p(v) t \text { otherwise }
\end{array}\right.
$$




\section{Results and discussion}

For the purpose of spatio-temporal analysis of wind and solar energy source complementarity we have neglected the maximal capacity of each region to accommodate given energy source and assumed a uniform distribution of $2 \mathrm{MW}$ wind parks and $2 \mathrm{MW}$ PV installations across the whole voivodship (in each squared region $2 \mathrm{MW}$ in WTs and 2 MW in PVs). After that we have investigated the value of the coefficient of correlation between aggregated (from all 74 regions) wind and solar energy yield as well as the observed load on an hourly, daily and monthly time scale. Obtained results are presented in Table 1 whereas Figure 3 visualizes the annual variability of those three phenomena.

As can be observed in Table 1 the all considered phenomena (load, and energy of solar radiation and wind speed) does not exhibit any significant correlation on an hourly time scale. This implies that from the perspective of the whole voivodeship it is very unlikely that the wind or solar generation will follow the load profile. This will result in a situation in which energy surpluses (supply from WTs and PVs is greater than demand) and deficits (supply from WTs and PVs is smaller than the demand) will occur. In such circumstances it might be very hard to optimize the operation of the whole energy system. Therefore, it will be mandatory to use some form of energy storage which will compensate for the varying energy output and changing energy demand. On a daily time scale (which considered the daily sums of energy generated by PVs and WTs as well as the whole daily energy consumption) we have observed a negative correlation between the load and the energy yield from PVs. This may indicate that usually days with higher observed values of irradiation will be simultaneously days when lower demand is observed. However, this not necessarily must be true because the energy demand patterns are changing and it is being observed that not only low temperatures (winter period) lead to an increase in energy consumption but also high ones [32]. This indicates a strong potential for PVs to cover peak loads resulting from intensive utilization of air-conditioning.

Table 1. Wind and solar energy complementarity and their relation to the load.

\begin{tabular}{|c|c|c|c|c|c|c|}
\cline { 2 - 7 } \multicolumn{1}{c|}{} & \multicolumn{4}{c|}{ Time scale } \\
\cline { 2 - 7 } \multicolumn{1}{c|}{} & \multicolumn{2}{c|}{ Hourly } & \multicolumn{2}{c|}{ Daily } & \multicolumn{2}{c|}{ Monthly } \\
\cline { 2 - 7 } & Solar & Load & Solar & Load & Solar & Load \\
\hline Wind & 0.0975 & 0.1631 & -0.299 & 0.1319 & -0.6714 & 0.7264 \\
\hline Solar & $\mathrm{X}$ & 0.1835 & $\mathrm{X}$ & -0.4999 & $\mathrm{X}$ & -0.9210 \\
\hline
\end{tabular}

The results of the energy yield and demand based on monthly means is presented on Fig. 4. As can be observed the load pattern does not exhibit any significant variability (for further reading on its changes we refer the interested readers to [32]). Therefore on a monthly time scale PVs exhibit a significant negative correlation with the energy demand. However, a positive (beneficial) positive $\mathrm{CC}$ value between load and wind energy is also observed. This indicated that the annual pattern of wind energy generation tends to follow the load. The analysis on a monthly scale also provides us with information on the complementarity between solar and wind energy sources. Observed here value of CC (0.67) indicates that this interchangeability is not perfect and there is a need to couple both of those energy sources with a large scale energy storing device. An additional correlation analysis was performed for combined energy yield from PVs and WTs with the energy demand. The observed values of $\mathrm{CC}$ ranged from slightly above 0 to 0.2 which shows that energy generation from those two variable energy sources does not exhibit any significant 
correlation with load. This lead to a conclusions that without other measures/techniques in form of: energy storage, V2G, DMS or energy yield forecasting the integration of those to VRES based purely on their complementary will be a very complicated task.

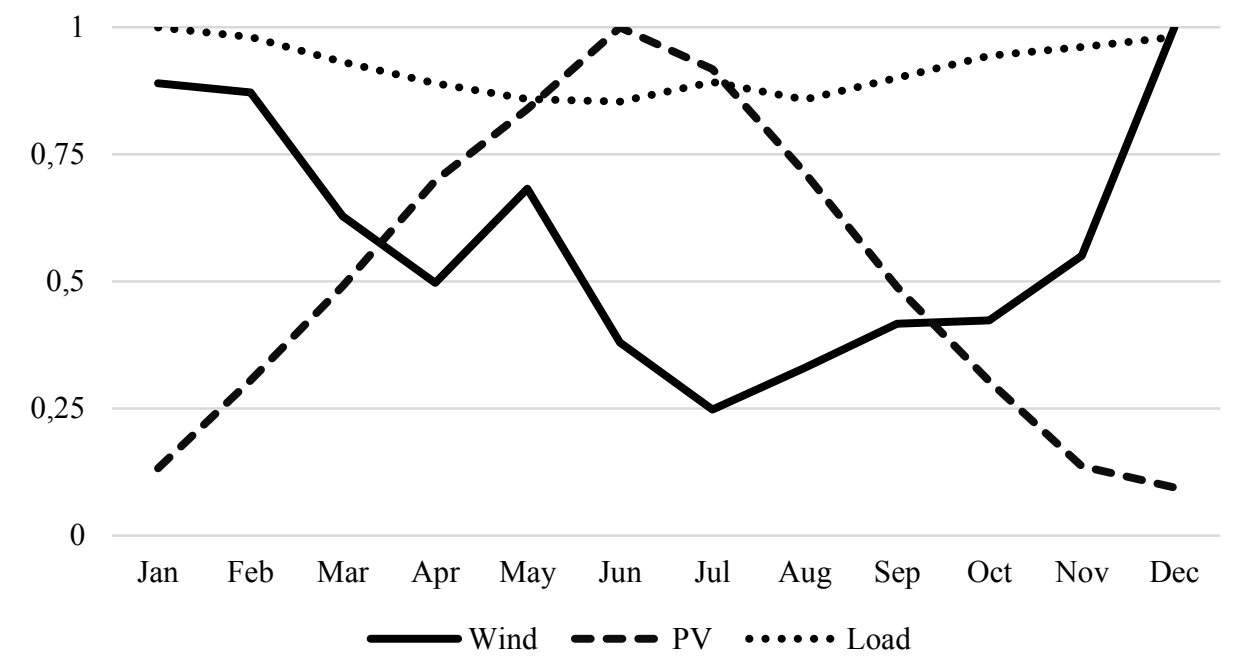

Fig.4. Normalized monthly values of wind and solar energy yield from all 74 regions juxtaposed to the load.

On the Fig. 5 we have presented separately the coefficient of correlation between hourly energy yield from PVs and wind generation in function of distance between individual considered sites. Results indicate that in the investigated area the solar and wind energy sources does not exhibit complementarity on a spatial scale. Values of CC smaller than 1 may only lead to smoothing the energy generation curve. Such phenomena can be observed based on the coefficient of variability (CV) which for hourly wind generation values has been reduced by $6 \%$ (from $128 \%$ in case of mean CV calculated for each $k$ separately to $122 \%$ calculated for aggregated wind generation from all sites). For PVs this smoothing effect was slightly smaller and amounted to $3 \%$ (a reduction from $88 \%$ to $85 \%$ ).
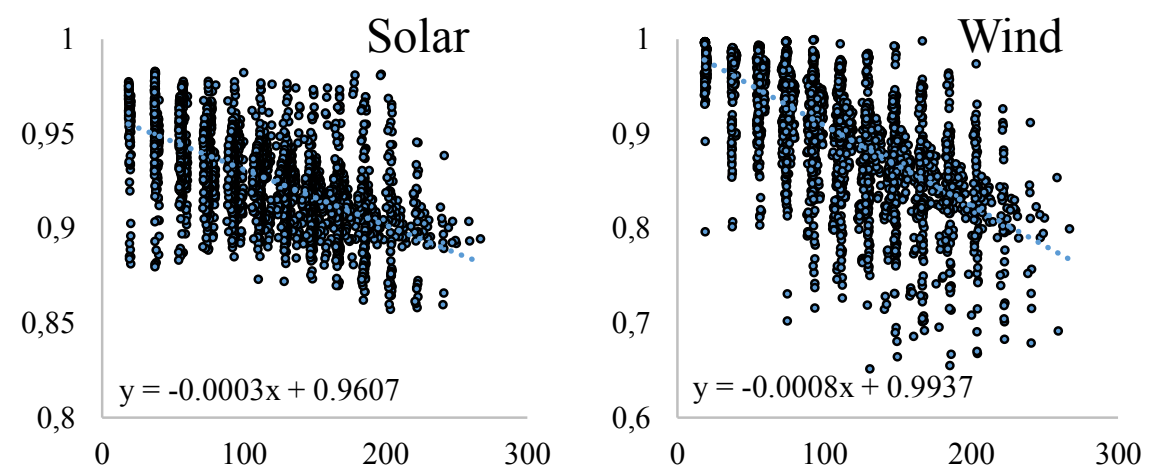

Fig.5. Solar and wind energy yield spatial complementarity, (OY) coefficient of correlation, (OX) distance between sites in kilometres. 


\section{Conclusions}

Conducted here analysis is the first step to assessing the possibility of covering the energy demand of whole Lower Silesia based purely on wind, solar and hydropower (abundant here due to the proximity of mountain ranges) and energy storage in form of pumpedstorage hydroelectricity. Conducted preliminary calculations has shown that existing temporal complementarity of wind and solar energy sources combined with energy storage in form of PSH may be a good basis for PV-WT-PSH hybrid development.

\section{References}

1. L.E. Jones, Renewable energy integration: practical management of variability, uncertainty, and flexibility in power grids (Academic Press, 2014).

2. M.Z. Jacobson, M.A. Delucchi, Energ policy, 39, 3 (2011).

3. T. Brown, D. Schlachtberger, A. Kies, M. Greiner, Sector Coupling in a Highly Renewable European Energy System (15th Wind Integration Workshop, Vienna, 2017).

4. J. Jurasz, B. Ciapała, Appl Energ, 198 (2017).

5. A. Kies, B.U. Schyska, L. von Bremen, Energies, 9, 11 (2016).

6. J. Jurasz, J. Mikulik, Architecture, Civil Engineering, Environment, 4 (2015).

7. R. Szczerbowsk, B. Ceran, E3S Web Con, 10, 00090 (2016).

8. A. Cavallo, Ener, 32, 2 (2007).

9. J. Jurasz, J. Mikulik, M. Krzywda, E3S Web Con, 17, 00035 (2017).

10. X. Wu, X. Hu, S. Moura, X. Yin, V. Pickert, J. Power Sour, 333 (2016).

11. J. Kleissl, Solar energy forecasting and resource assessment (Academic Press, 2013).

12. X. Wang, P. Guo, X. Huang, Energy procedia, 12 (2011).

13. C.E. Hoicka, I.H. Rowlands, Renew Energ, 36, 1 (2011).

14. F. Monforti, T. Huld, K. Bódis, L. Vitali, M. D'isidoro, R. Lacal-Arántegui, Renew Energ, 63 (2014).

15. P. De Jong, A.S. Sánchez, K. Esquerre, R.D.A. Kalid, E.A. Torres, Renew Sust Energ Rev, 23 (2013).

16. Y. Liu, L. Xiao, H. Wang, S. Dai, Z. Qi, Sci China Technol Sc, 56, 3 (2013).

17. Y. Li, V.G. Agelidis, Y. Shrivastava, Wind-solar resource complementarity and its combined correlation with electricity load demand (4th IEEE Conference on Industrial Electronics and Applications, 2009).

18. S. Jerez, R.M. Trigo, A. Sarsa, R. Lorente-Plazas, D. Pozo-Vázquez, J.P. Montávez, Energy Procedia, 40, 48-57 (2013).

19. P.S. dos Anjos, A.S.A. da Silva, B. Stošić, T. Stošić, Physica A, 424 (2015).

20. K. Engeland, M. Borga, J.D. Creutin, B. François, M.H. Ramos, J.P. Vidal, Renew Sust Energ Rev, 79 (2017).

21. R. Hyrzyński, M. Karcz, M. Lemański, K. Lewandowski, S. Nojek, Acta Energetica, 4, 17 (2013).

22. J. Jurasz, A. Piasecki, Acta Energetica, 2, 27 (2016).

23. M. Bajor, P. Ziołkowski, G. Widelski, Acta Energetica, 3, 28 (2016).

24. J. Jurasz, A. Piasecki, M. Wdowikowski, E3S Web Con, 10, 00032 (2016).

25. J. Jurasz, J. Mikulik, Przegląd Elektrotechniczny 93, 7 (2017).

26. http://www.soda-pro.com

27. http://www.imgw.pl/

28. E.W. Peterson, J.P. Hennessey Jr, J Appl Meteorol, 17, 3 (1978).

29. http://www.pse.pl/ 
30. M. Hanif, M. Ramzan, M. Rahman, M. Khan, M. Amin, M. Aamir, ISESCO J Sci Technol, 8, 14 (2012).

31. J.A. Duffie, W.A. Beckman, Solar engineering of thermal processes (New York Wiley Interscience, 1991).

32. J. Jurasz, J. Mikulik, A. Piasecki, Przegląd Elektrotechniczny, 92, 9 (2016). 